\title{
Aqueous Synthesis of Ru Doped Hematite Nanostructures: A Morphological, Structural, Optical, and Magnetic Study
}

\author{
Ceboliyozakha Leonard Ndlangamandla, ${ }^{1,2}$ Krish Bharuth-Ram, ${ }^{3}$ \\ Osman Muzi Ndwandwe, ${ }^{1}$ Balla Diop Ngom, ${ }^{2,4}$ and Malik Maaza ${ }^{2,4}$ \\ ${ }^{1}$ Department of Physics and Engineering, University of Zululand, Private Bag X1001, Kwadlangezwa 3886, South Africa \\ ${ }^{2}$ Nanosciences African Network (NANOAFNET), iThemba LABS, National Research Foundation, P.O. Box 722, Somerset West, \\ Western Cape 7129, South Africa \\ ${ }^{3}$ Physics Department, Durban University of Technology, Durban 4001, South Africa \\ ${ }^{4}$ UNESCO-UNISA Africa Chair in Nanosciences and Nanotechnology, College of Graduate Studies, University of South Africa, \\ Muckleneuk Ridge, P.O. Box 392, Pretoria 0002, South Africa \\ Correspondence should be addressed to Ceboliyozakha Leonard Ndlangamandla; cebondlangamandla@gmail.com
}

Received 12 December 2014; Revised 11 May 2015; Accepted 25 May 2015

Academic Editor: Fabien Grasset

Copyright (C) 2015 Ceboliyozakha Leonard Ndlangamandla et al. This is an open access article distributed under the Creative Commons Attribution License, which permits unrestricted use, distribution, and reproduction in any medium, provided the original work is properly cited.

\begin{abstract}
Hematite nanorods doped with ruthenium were successfully deposited on fluorine doped tin oxide (FTO) glass substrates using aqueous chemical growth. Using complementary surface/interface investigation techniques, the Ru incorporation in the Ru- $\alpha$ $\mathrm{Fe}_{2} \mathrm{O}_{3}$ nanorods was evidenced. The optical band gap was found to be Ru doping concentration dependent: varying from 2.32 (2) to 2.47 (2) $\mathrm{eV}$. These band gap values are well suited for the targeted water splitting process without application of an external bias.
\end{abstract}

\section{Introduction}

Hematite $\left(\alpha-\mathrm{Fe}_{2} \mathrm{O}_{3}\right)$ is the thermodynamically stable crystallographic phase of ferric oxide. It is earth abundant, nontoxic, and photocorrosive resistant and is an efficient photocatalytic material [1]. Because of the bulk band gap of 1.9-2.2 eV, hematite was recognized as an ideal candidate as photoanode material in a Photoelectrochemical Cell (PEC) for the production of hydrogen by solar water splitting process.

Thin films of hematite, consisting of crystalline arrays of oriented nanorods [2], have been demonstrated to display efficient photovoltaic properties [2]. In view of the relatively large charge carrier free mean path and e-hole recombination, these oriented nanorods provide better transport and collection of photogenerated electrons, exhibiting substantial photocurrent efficiency. A higher level of engineering of $\alpha-\mathrm{Fe}_{2} \mathrm{O}_{3}$ based nanomaterials, such as 3 -dimensional and anisotropic oriented arrays, is currently under investigation for additional potential technological applications in electronics, photonics, and magnetic devices. Current methods of preparation of such nanorods involve various approaches, such as chemical vapour deposition [3], sol-gel processes [4], pulsed laser evaporation [5], reactive sputtering [6], hydrothermal techniques [7], spray pyrolysis [8], and aqueous chemical growth (ACG) [9]. In the present study, ACG, also known as Vayssieres method, was adopted to grow hematite nanorods, because it is a simple technique for nanostructure deposition at relatively low temperatures. Advantages of the ACG method include the utilization of nonexpensive equipment, nontoxic reagents, nonhazardous byproducts, and surfactant-free surfaces. The morphology, shape, size, and structure of grown nanostructures can be tailored by adjusting growth parameters, such as the concentration of the solution, the reagent stoichiometry, the temperature, and the $\mathrm{pH}[10]$. The present study focusses on the effects of Ru doping on the optical, morphological, and structural properties of hematite nanorods.

\section{Experimental Procedure}

2.1. Material Synthesis. As was mentioned previously, the nanostructured thin films of $\alpha-\mathrm{Fe}_{2} \mathrm{O}_{3}$ were synthesized on 


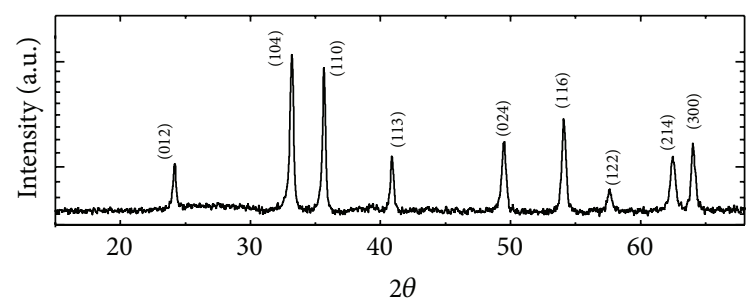

(a)

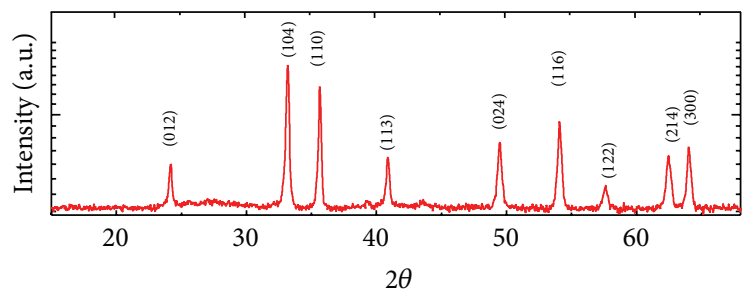

(b)

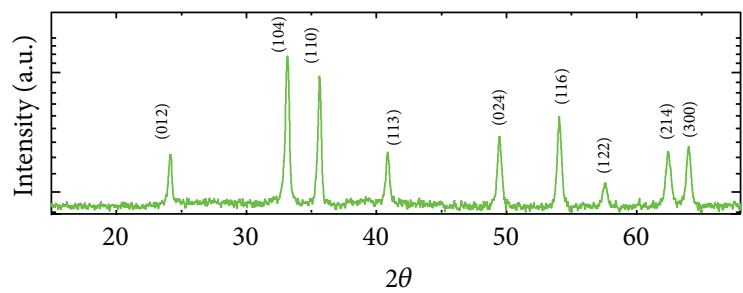

(c)

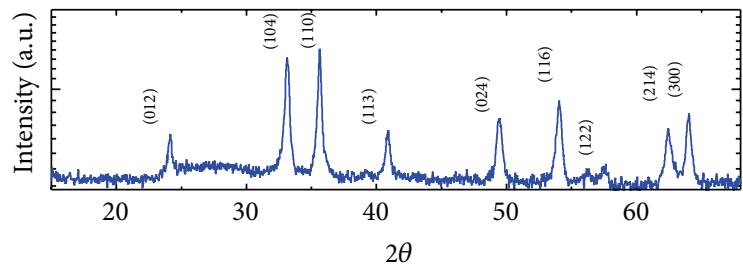

(d)

FIgURE 1: $2 \theta$ XRD scans of hematite powder samples grown on TCO glass for $24 \mathrm{~h}$ at $95^{\circ} \mathrm{C}$, as a function of dopant concentration: (a) undoped film, (b), (c), and (d) synthesized, respectively, with $0.006 \mathrm{~g}, 0.018 \mathrm{~g}$, and $0.030 \mathrm{~g}$ of $\mathrm{RuCl}_{3} \cdot x \mathrm{H}_{2} \mathrm{O}$ salt as doping precursor.

fluorine doped tin oxide (FTO) glass substrates using the ACG method. The commercially high grade chemicals (purchased from Industrial Analytical Ltd.) used in the synthesis were ferric chloride $\left(\mathrm{FeCl}_{3}\right)$, sodium nitrate $\left(\mathrm{NaNO}_{3}\right)$, and ruthenium chloride $\left(\mathrm{RuCl}_{3} \cdot x \mathrm{H}_{2} \mathrm{O}\right)$. The precursor concentrations used in the synthesis were 0.1 Molar of anhydrous $\mathrm{FeCl}_{3}$ and 1 Molar of $\mathrm{NaNO}_{3}$. The deposition temperature was set at $95^{\circ} \mathrm{C}$. FTO substrates cut to the required dimensions $(25 \times$ $25 \mathrm{~mm}^{2}$ ) were cleaned by ultrasonic washing and degreased with trichloroethylene, acetone, and methanol consecutively. The clean substrates were immersed into $100 \mathrm{~mL}$ aqueous solution (MilliQ, $18.2 \mathrm{M} \Omega \mathrm{cm}$ ) of $\mathrm{FeCl}_{3}$ and $\mathrm{NaNO}_{3}(\mathrm{pH}$ of 1.5) and placed in a standard laboratory oven at a constant temperature of $95^{\circ} \mathrm{C}$ for different deposition times. The $\mathrm{pH}$ of 1.5 allows the growth of perpendicularly oriented nanorods with the longest length and the smallest diameter $[12,13]$. The resultant thin films were thoroughly washed with deionized

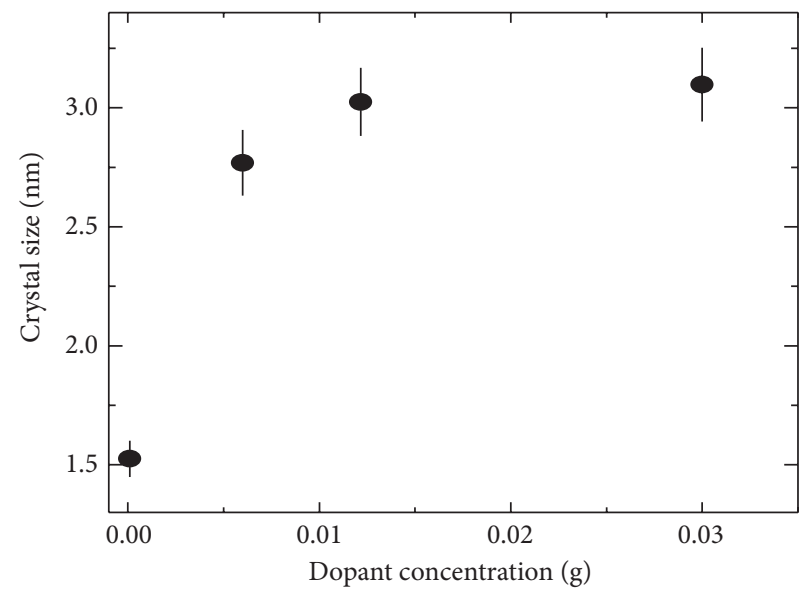

FIGURE 2: Average basal size of the grown nanorods as a function of doping, estimated from the width of the (104) Bragg peak.

water to remove any residual salts and then dried at $95^{\circ} \mathrm{C}$ for $1 \mathrm{~h}$. The thin films were heat treated in air at $500^{\circ} \mathrm{C}$ for $1 \mathrm{~h}$ to obtain the desired stoichiometric and thermodynamically stable hematite phase of $\alpha-\mathrm{Fe}_{2} \mathrm{O}_{3}$.

2.2. Material Characterization. The crystallinity of the deposited iron oxide thin films was characterized by X-ray diffraction (XRD), using a Bruker AXS D8 Advance X-ray diffractometer with $\mathrm{CuK} \alpha$ radiation $(\lambda=1.541 \AA)$. The XRD data were collected with a position sensitive detector (PSD) at scan steps of $0.007^{\circ}$ and scan speed of $1 \mathrm{step} / \mathrm{s}$. The morphology of the films was studied using a Leo-Stereo Scan 440 Scanning Electron Microscope (SEM), while the chemical composition and physical properties of the $\alpha$ - $\mathrm{Fe}_{2} \mathrm{O}_{3}$ particles were investigated using Raman spectroscopy and Mössbauer spectroscopy. The Mössbauer spectra of the samples were collected in transmission mode using a $15 \mathrm{mCi}$ ${ }^{57} \mathrm{CoRh}$ source. UV-VIS-NIR optical measurements, both direct transmission $(T)$ and absorption $(A)$, were carried out within the spectral range of $200-1100 \mathrm{~nm}$, at room temperature on a Cecil 2000 spectrophotometer.

\section{Results and Discussion}

3.1. Crystallographic Structure and X-Rays Diffraction. Figure 1 reports the $2 \theta$ XRD scans of the hematite nanostructures for the various $\mathrm{Ru}$ doping concentrations. According to the JCPDC database, number 73-0603 and number 1309-37-1 of $\alpha-\mathrm{Fe}_{2} \mathrm{O}_{3}$, the peaks corresponding to the values of $2 \theta$ equal to $24.14^{\circ}, 33.15^{\circ}, 35.61^{\circ}, 39.28^{\circ}$, $40.86^{\circ}, 49.48^{\circ}, 54.09^{\circ}, 56.15^{\circ}, 57.59^{\circ}, 62.45^{\circ}$, and $63.99^{\circ}$ can be assigned to the following reticular planes: (012, $104,110,024,116,214,113,018,134,1010,220$, and 300), respectively. The intensity of the component along the (104) plane indicates that the $\mathrm{Ru}$ doped hematite particles are oriented in $\{104\}$ direction. The intensity of this strongest peak tends to decrease and its line width broadens as the $\mathrm{Ru}$ dopant concentration increases. More precisely, the (104) Bragg peak becomes less intense than the (110) and hence 


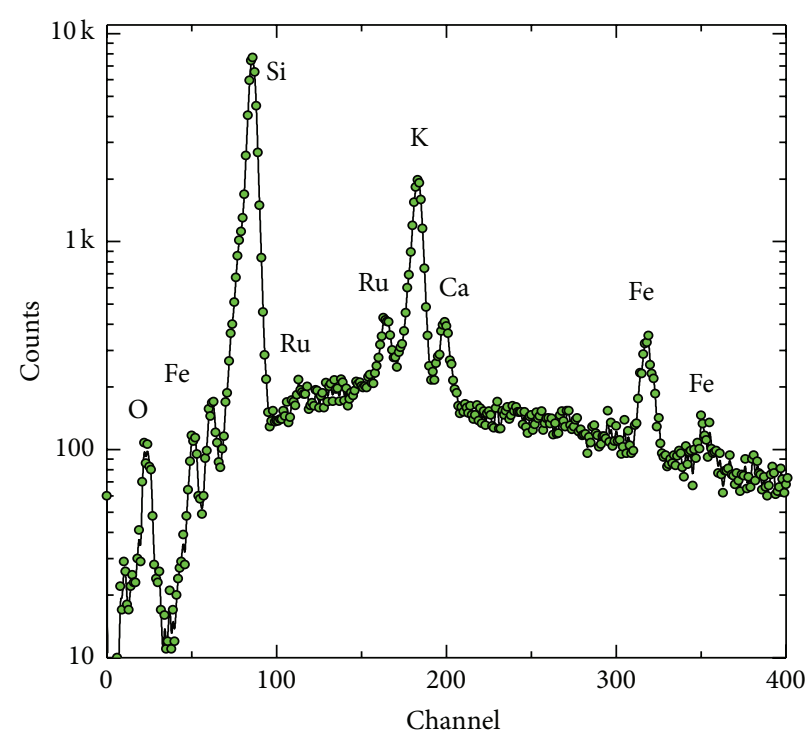

FIGURE 3: Typical EDS profile of Ru doped hematite samples.
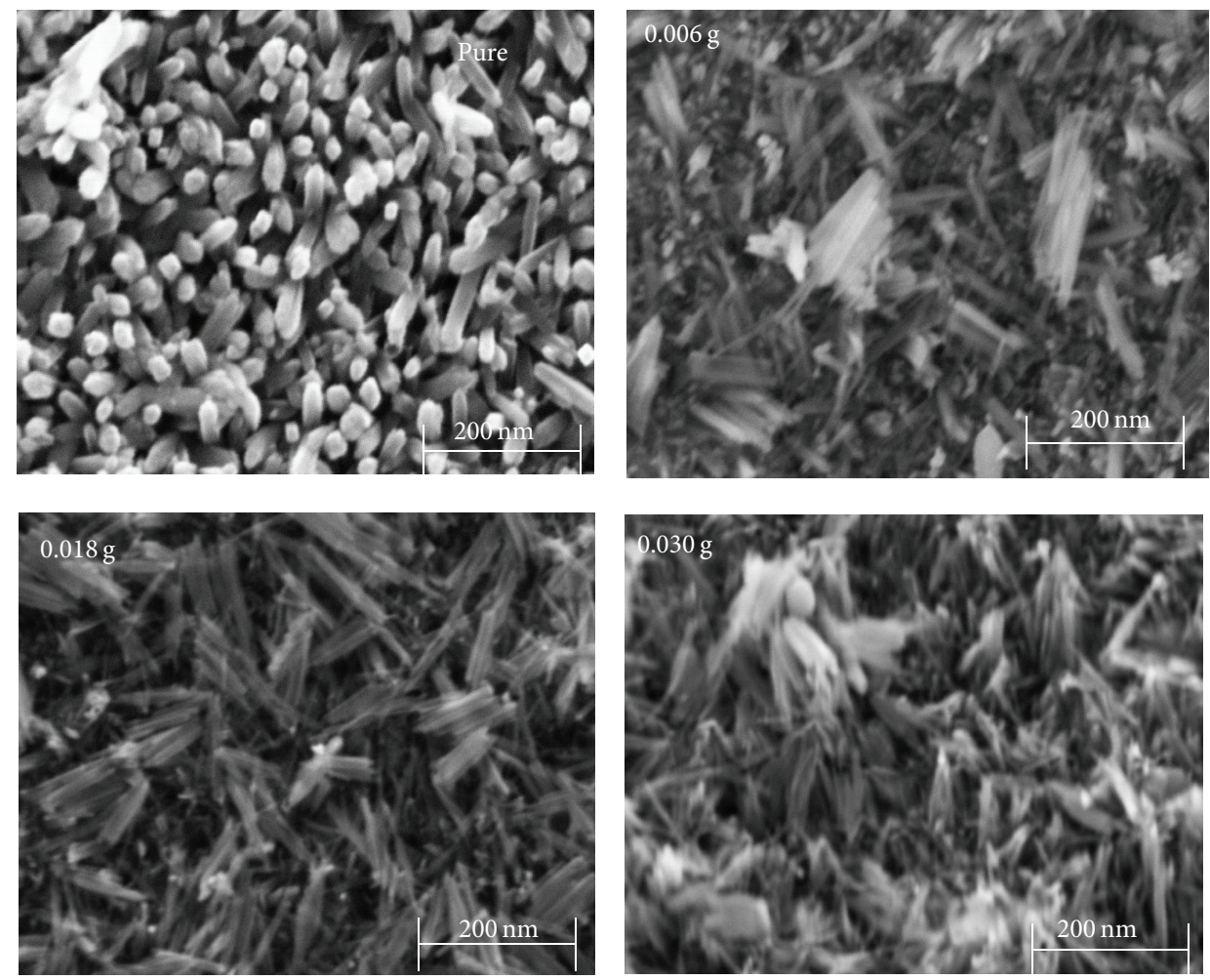

FIgure 4: The SEM images of the undoped and Ru doped $\alpha-\mathrm{Fe}_{2} \mathrm{O}_{3}$ samples grown on FTO glass substrate for $24 \mathrm{~h}$ at $95^{\circ} \mathrm{C}$. The amount of $\mathrm{RuCl}_{3} \cdot x \mathrm{H}_{2} \mathrm{O}$ precursor is indicated on each image.

reflecting a change of texture. This is probably due to the interstitial substitution of the $\mathrm{Ru}$ atom and the resulting structural disorder induced in the hematite crystal structure. There is no evidence of XRD reflections from $\mathrm{RuO}_{2}$, which confirms the purity of the doped $\alpha-\mathrm{Fe}_{2} \mathrm{O}_{3}$. The width at half maximum (FWHM) of (104) reflection line was used in Scherrer's equation to estimate the basal average size of the nanorods $\langle\mathrm{D}\rangle$. Its variation with the Ru doping concentration is presented in Figure 2. As one can notice, $\langle\mathrm{D}\rangle$ increases rapidly until reaching a saturation value. As highlighted by Vayssieres et al. $[12,13]$, this is due to the $\mathrm{pH}$ and growth mode.

Figure 3 reports a typical Energy Dispersive X-Rays Spectroscopy (EDS) profile of the Ru doped samples. The reflections due to ruthenium $(\mathrm{Ru})$, iron $(\mathrm{Fe})$, and oxygen $(\mathrm{O})$ are clearly evidenced. The peaks assigned to $\mathrm{Si}, \mathrm{Ca}$, and $\mathrm{K}$ 


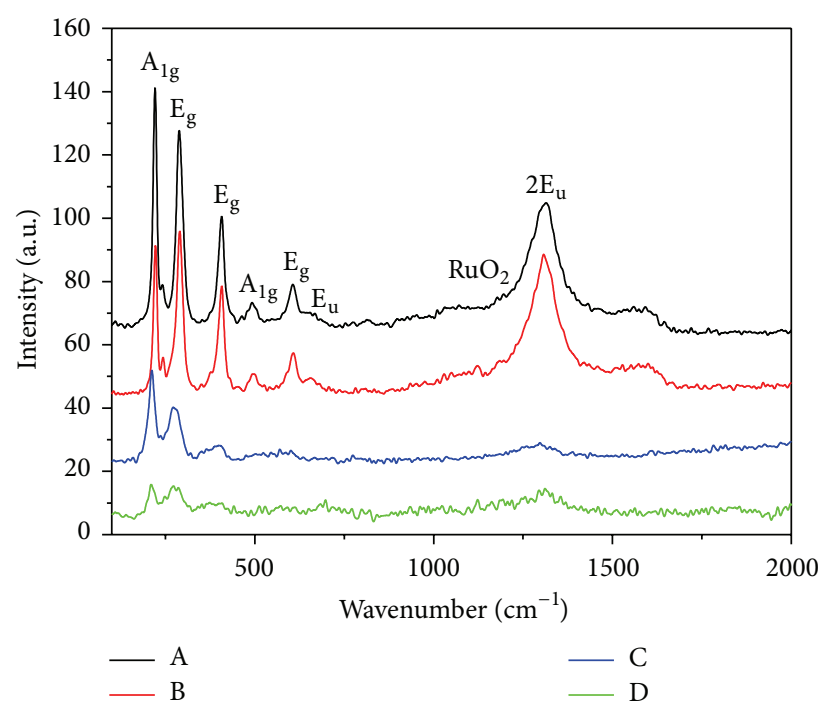

FIgURE 5: Raman shifts of $\mathrm{Ru}$ doped hematite $\left(\mathrm{Ru}-\alpha-\mathrm{Fe}_{2} \mathrm{O}_{3}\right)$ nanorods grown for $24 \mathrm{~h}$ on FTO glass substrate: (A) pure and doped $\alpha-\mathrm{Fe}_{2} \mathrm{O}_{3}$, (B) $0.006 \mathrm{~g}$, (C) $0.018 \mathrm{~g}$, and (D) $0.030 \mathrm{~g}$ of the doping precursor.

are due to reflections from the glass substrate. The atomic concentrations of Ru in the samples were estimated to be 0.14 , 0.08 , and 0.06 at.\% for the samples synthesized with $0.030 \mathrm{~g}$, $0.018 \mathrm{~g}$, and $0.006 \mathrm{~g}$ of $\mathrm{RuCl}_{3} \cdot x \mathrm{H}_{2} \mathrm{O}$ precursor, respectively.

Figure 4 reports the SEM images of the undoped and the various $\mathrm{Ru}$ doped hematite samples. All samples exhibit the expected morphology and shape anisotropy of the synthesized particles: nanorods. Likewise, it can be noted that the higher the doping is, the more random the orientation of the nanorods is. Yet this misorientation is effective; it would not a priori affect the carrier charge free mean path but would enhance the light trapping due to multiple scattering. Consequentially, the overall water photosplitting efficiency would be high accordingly.

\subsection{Raman Analysis on Ru Doped Hematite Nanorods.}

The Raman spectra for $\mathrm{Ru}$ doped hematite samples are shown in Figure 5. All vibrational modes for hematite are present, as summarized in Table 1 . The intensity of the $\mathrm{E}_{\mathrm{g}}$ (1) vibrational mode, positioned at $288 \mathrm{~cm}^{-1}$, decreases with increasing dopant concentration. The vibrational mode around $1124 \mathrm{~cm}^{-1}$ is due to $\mathrm{Ru}-\mathrm{O}$ bonds as reported by Jo et al. (2005) [11]. The higher the dopant concentration, the lesser the intensity and the broader the width of the vibration modes. This indicates the loss of crystallinity in the samples when the dopant concentrations increase at least locally. This could be correlated to the broadening of the XRD patterns as reported above.

3.3. Analysis of Mössbauer Spectra. Mössbauer spectra of the unheated and heated $\mathrm{Ru}$ doped samples are presented in Figures 6 and 7, respectively. The spectra were analysed with the analysis code RECOIL [14], using Lorentzian line shapes. The hyperfine parameters extracted from the fits to

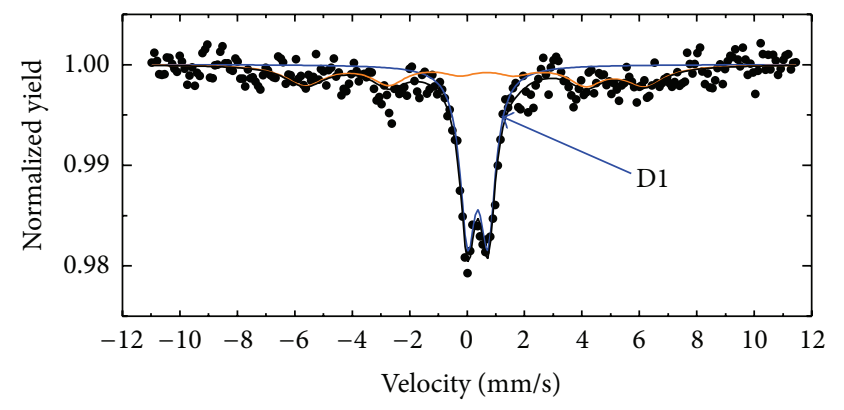

(a) $0.006 \mathrm{~g}$ Ru as-synthesized

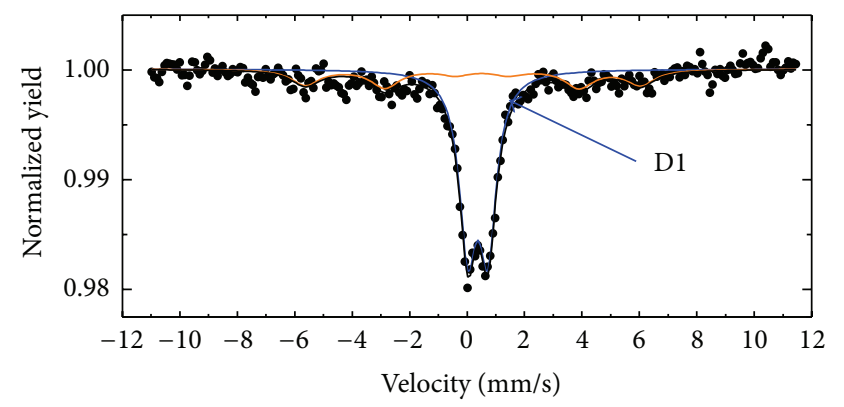

(b) $0.018 \mathrm{~g}$ Ru as-synthesized

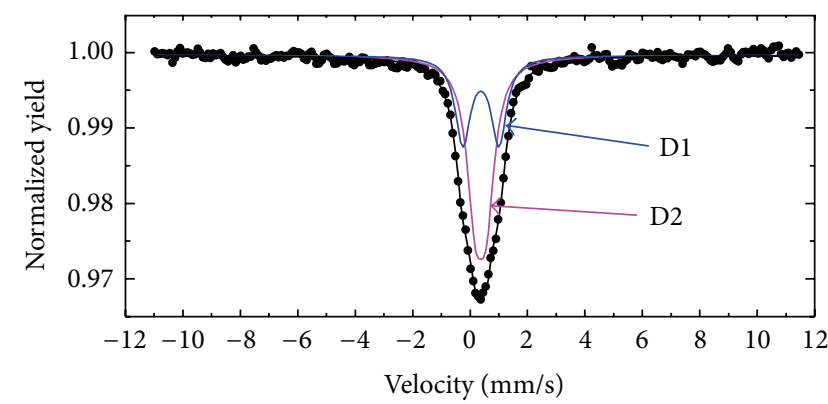

(c) $0.030 \mathrm{~g} \mathrm{Ru}$ as-synthesized

FIGURE 6: Mössbauer spectra of the as-synthesized (unheated) Ru doped iron oxide powder samples deposited for $24 \mathrm{~h}$, using the precursor concentrations shown.

TABle 1: The Raman shifts $\left(\mathrm{cm}^{-1}\right)$ for the $\mathrm{Ru}$ doped hematite nanorods grown for $24 \mathrm{~h}$ on FTO glass substrate, where A presents data for pure $\mathrm{Fe}_{2} \mathrm{O}_{3}, \mathrm{~B}$ for $0.006 \mathrm{~g}$, C for $0.018 \mathrm{~g}$, and D for $0.030 \mathrm{~g}$ precursor doped samples.

\begin{tabular}{lcccc}
\hline Vibrational mode & A (undoped) & $\mathrm{B}$ & $\mathrm{C}$ & $\mathrm{D}$ \\
\hline $\mathrm{A}_{\mathrm{lg}}(1)$ & 221.2 & 222.2 & 210.2 & 212.1 \\
$\mathrm{E}_{\mathrm{g}}(1)$ & 241.9 & 243.4 & - & - \\
$\mathrm{E}_{\mathrm{g}}(1)$ & 288.5 & 289.9 & 272.4 & 271.9 \\
$\mathrm{E}_{\mathrm{g}}(1)$ & 407.5 & 407.5 & 374.3 & 398.7 \\
$\mathrm{~A}_{\mathrm{lg}}(2)$ & 492.3 & 494.6 & - & - \\
$\mathrm{E}_{\mathrm{g}}(1)$ & 606.6 & 607.5 & - & - \\
$\mathrm{E}_{\mathrm{u}}$ & 654 & 655.9 & - & - \\
$2 \mathrm{E}_{\mathrm{u}}$ & 1314 & 1307.8 & 1311.9 & 1311.9 \\
\hline
\end{tabular}

the spectra are presented in Table 2, in which the isomer shifts are expressed relative to $\alpha$-Fe. 
TABLE 2: Mössbauer parameters (isomer shift (CS), quadrupole splitting (QS), hyperfine field $(H)$, line width (HWHM), and area fraction (A)) extracted from the fits to the spectra displayed in Figures 6 and 7, of the Ru doped $\alpha-\mathrm{Fe}_{2} \mathrm{O}_{3}$ samples synthesized with the precursor concentrations shown. The isomer shifts are expressed relative to $\alpha$-Fe.

\begin{tabular}{|c|c|c|c|c|c|c|}
\hline Sample & Component & $\begin{array}{c}\mathrm{CS} \\
(\mathrm{mm} / \mathrm{s})\end{array}$ & $\begin{array}{c}\text { QS/e } \\
(\mathrm{mm} / \mathrm{s})\end{array}$ & $\begin{array}{c}H \\
(\mathrm{~T})\end{array}$ & $\begin{array}{c}\mathrm{G} / 2 \\
(\mathrm{~mm} / \mathrm{s})\end{array}$ & $\begin{array}{c}\mathrm{A} \\
(\%)\end{array}$ \\
\hline \multicolumn{7}{|c|}{ (a) As-synthesized } \\
\hline \multirow{2}{*}{$0.006 \mathrm{~g}$} & D1 & $0.37(1)$ & $0.70(5)$ & - & 0.32 & $59(3)$ \\
\hline & $\mathrm{B} 1$ & $0.5(1)$ & $-0.2(1)$ & $3.66(2)$ & 0.70 & $41(4)$ \\
\hline \multirow{2}{*}{$0.018 \mathrm{~g}$} & D1 & $0.37(1)$ & $0.68(1)$ & - & 0.34 & $78(4)$ \\
\hline & $\mathrm{B} 1$ & $0.3(1)$ & $-0.1(1)$ & $3.25(8)$ & 0.60 & $22(4)$ \\
\hline \multirow{2}{*}{$0.030 \mathrm{~g}$} & $\mathrm{D} 1$ & $0.37(1)$ & $0.40(4)$ & - & 0.38 & $69(2)$ \\
\hline & $\mathrm{D} 2$ & $0.38(2)$ & $1.28(5)$ & - & 0.30 & $31(3)$ \\
\hline$\alpha-\mathrm{Fe}_{2} \mathrm{O}_{3}$ & $\mathrm{~B} 1$ & $0.355(6)$ & $-0.11(1)$ & $5.156(3)$ & 0.18 & 100 \\
\hline \multicolumn{7}{|c|}{ Annealed at $500^{\circ} \mathrm{C}$} \\
\hline \multirow[t]{2}{*}{$0.006 \mathrm{~g}$} & $\mathrm{~B} 1$ & $0.36(1)$ & $-0.12(1)$ & $5.16(1)$ & 0.17 & 100 \\
\hline & B1 & $0.36(1)$ & $0.02(2)$ & $5.11(2)$ & 0.19 & $49(2)$ \\
\hline \multirow{3}{*}{$0.018 \mathrm{~g}$} & B2 & $0.33(2)$ & $0.16(2)$ & $5.24(2)$ & 0.14 & $19(2)$ \\
\hline & B3 & $0.43(2)$ & $0.36(3)$ & $4.20(6)$ & 0.35 & $18(2)$ \\
\hline & B4 & $0.26(2)$ & $-0.06(3)$ & $4.22(6)$ & 0.35 & $14(2)$ \\
\hline \multirow{2}{*}{$0.030 \mathrm{~g}$} & B1 & $0.36(4)$ & $0.34(2)$ & $5.12(2)$ & 0.15 & $70(2)$ \\
\hline & B2 & $0.30(4)$ & $-0.05(6)$ & $5.26(2)$ & 0.14 & $30(2)$ \\
\hline
\end{tabular}

The spectra of the as-synthesized samples consist of doublets whose isomer shifts and quadrupole splittings are close to those of $\beta-\mathrm{Fe}_{2} \mathrm{O}_{3}$ [15]. However, in the case $\beta-\mathrm{Fe}_{2} \mathrm{O}_{3}$ the two subspectra have quadrupole shifts of 0.69 and $0.90 \mathrm{~mm} / \mathrm{s}$, which are quite different from the values extracted from our fits to the spectrum obtained for the sample synthesized with $0.030 \mathrm{~g}$ of the $\mathrm{Ru}$ precursor (Figure 6(c)). This leads us to conclude that the synthesized thin films consist of nanoclusters of $\alpha-\mathrm{Fe}_{2} \mathrm{O}_{3}$ which display superparamagnetic relaxation in their RT spectra. On annealing at $500^{\circ} \mathrm{C}$, the nanoclusters morph into nanorods, as shown in Figure 4. The Mössbauer spectra evolve into magnetic sextets expected of multidomain structures. The spectra show some very interesting features. In the case of the $0.018 \mathrm{~g}$ doped sample, in addition to the main sextet with a hyperfine field close to that of $\alpha-\mathrm{Fe}_{2} \mathrm{O}_{3}$, the spectra also show approximately $30 \%$ contribution from components with lower field values with large line widths, presumably due to amorphous Fe(III) complexes. The main sextet consists of two subspectra. This is more clearly visible in the spectrum of the sample synthesized with $0.030 \mathrm{~g}$ of the precursor (Figure $7(\mathrm{~d})$ ). In addition to the sextet with a magnetic hyperfine field of $H=5.12 \mathrm{~T}$, a new sextet with $H=5.26 \mathrm{~T}$ is required to fit the data. This feature is very similar to that displayed in Figure 2 of [14], of pure synthetic hematite at $260 \mathrm{~K}$ (i.e., at the Morin temperature) showing the coexistence of the antiferromagnetic and weakly ferromagnetic phases. Our MS results, obtained in RT measurements, show that the $\mathrm{Ru}$ dopant raises the Morin temperature of hematite, in agreement with the observations reported by Helgason et al. [16], and provides further evidence that the $\mathrm{Ru}$ ions are incorporated in the $\alpha-\mathrm{Fe}_{2} \mathrm{O}_{3}$ structure.

3.4. Optical Properties of $R u$ Doped Hematite Nanorods. Figure 8 presents the UV-VIS-NIR optical transmissions of
$\mathrm{Ru}$ doped hematite thin film samples. The transmission decreases as the dopant increases; such a trend could be correlated with the higher orientation disorder induced by the $\mathrm{Ru}$ doping as observed previously in the SEM imaging. The corresponding optical absorbance spectra are presented in Figure 9. The latter were used to derive the optical band gap of the samples. It has been reported that the band edge position can be tailored by the electronegativity of the dopants as well as by quantum confinement effects. Figure 10 presents the plot of the $(\alpha h v)^{2}$ as a function of $h v$ from which the optical band gap of the Ru dope hematite nanorods was estimated to be $2.32 \mathrm{eV}$ and $2.36 \mathrm{eV}$ for the samples deposited with $0.006 \mathrm{~g}$ and $0.018 \mathrm{~g}$ of the precursor and for the sample prepared with $0.030 \mathrm{~g}$ of $\mathrm{RuCl}_{3} \cdot x \mathrm{H}_{2} \mathrm{O}$ it was found to be $2.48 \mathrm{eV}$. This indicates a shift within the range of $0.26-0.56 \mathrm{eV}$ for both samples prepared with 0.006 and $0.018 \mathrm{~g}$ of $\mathrm{RuCl}_{3} \cdot x \mathrm{H}_{2} \mathrm{O}$ doping precursor and $0.29-0.59 \mathrm{eV}$ for sample deposited with $0.030 \mathrm{~g}$ of $\mathrm{RuCl}_{3} \cdot x \mathrm{H}_{2} \mathrm{O}$ doping precursor. These shifts are in line with the targeted blue shift of the hematite band gap of about 0.3 to $0.6 \mathrm{eV}$ [12] which induce the upward shift of the conduction band edge. This substantial increase in the optical band gap could be due to a combination of the dopant as well as quantum confinement effects. It has been reported that the optimal band gap of $2.46 \mathrm{eV}[12,13]$ is required for water photooxidation without an external bias. Therefore, our obtained values would allow engineering a water splitting device without external bias.

\section{Conclusion}

The controlled growth of uniform $\mathrm{Ru}-\alpha-\mathrm{Fe}_{2} \mathrm{O}_{3}$ nanorods at a low temperature with soft chemistry deposition technique (ACG) was achieved. The XRD peak pattern broadening and the peak position shifts, because of increased dopant 


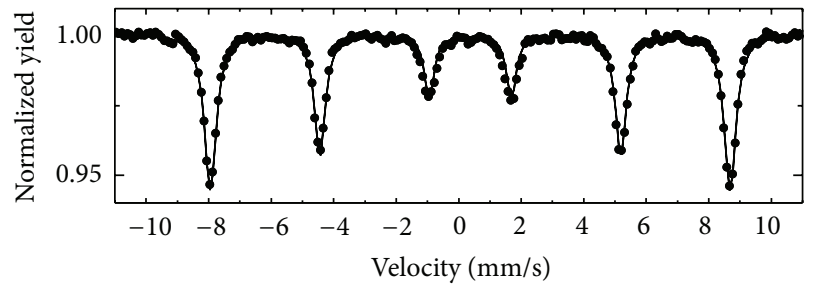

(a) $\alpha-\mathrm{Fe}_{2} \mathrm{O}_{3}$

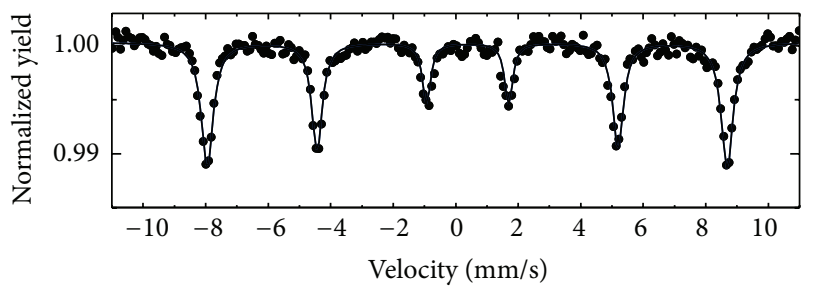

(b) $0.006 \mathrm{~g} \mathrm{Ru} . T_{A}=500^{\circ} \mathrm{C}$

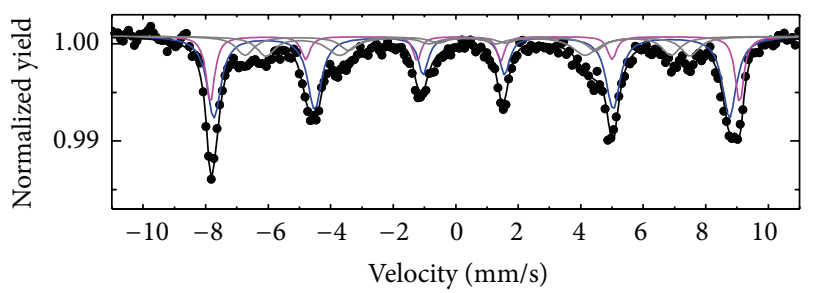

(c) $0.018 \mathrm{~g} \mathrm{Ru} . T_{A}=500^{\circ} \mathrm{C}$

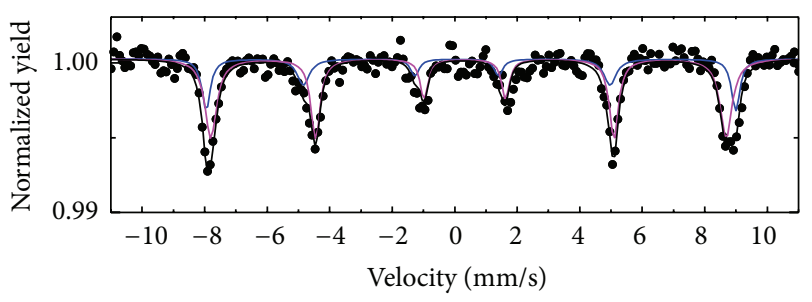

(d) $0.030 \mathrm{~g} \mathrm{Ru} . T_{A}=500^{\circ} \mathrm{C}$

FIGURE 7: Mössbauer spectra of Ru doped hematite powder samples after annealing at $500^{\circ} \mathrm{C}$. For comparison, the Mössbauer spectrum of undoped $\alpha-\mathrm{Fe}_{2} \mathrm{O}_{3}$ is also shown.

concentrations from $0.006 \mathrm{~g}$ to $0.030 \mathrm{~g}$, were observed. Strong evidence of the ruthenium presence in the hematite nanostructures was confirmed by SEM, EDS, and Raman measurements. The smaller magnetic field values on Mössbauer measurements due to the presence of the dopants were observed.

The optical band gap of the $\mathrm{Ru}$ dope hematite nanorods was estimated to be between $2.36 \mathrm{eV}$ and $2.48 \mathrm{eV}$ depending on ruthenium $\left(\mathrm{RuCl}_{3} \cdot x \mathrm{H}_{2} \mathrm{O}\right)$ concentrations. This suggests a band gap shift of about $0.16-0.58 \mathrm{eV}$ eV from the known hematite bulk band gap, which is between $1.9 \mathrm{eV}-2.2 \mathrm{eV}$, depending on the preparation process. These band gap shifts suggest that water splitting (which requires a band gap of $2.46 \mathrm{eV}$ ) without an external bias may be possible in these $\mathrm{Ru}$ doped nanosystems.

\section{Conflict of Interests}

The authors declare that there is no conflict of interests regarding the publication of this paper.

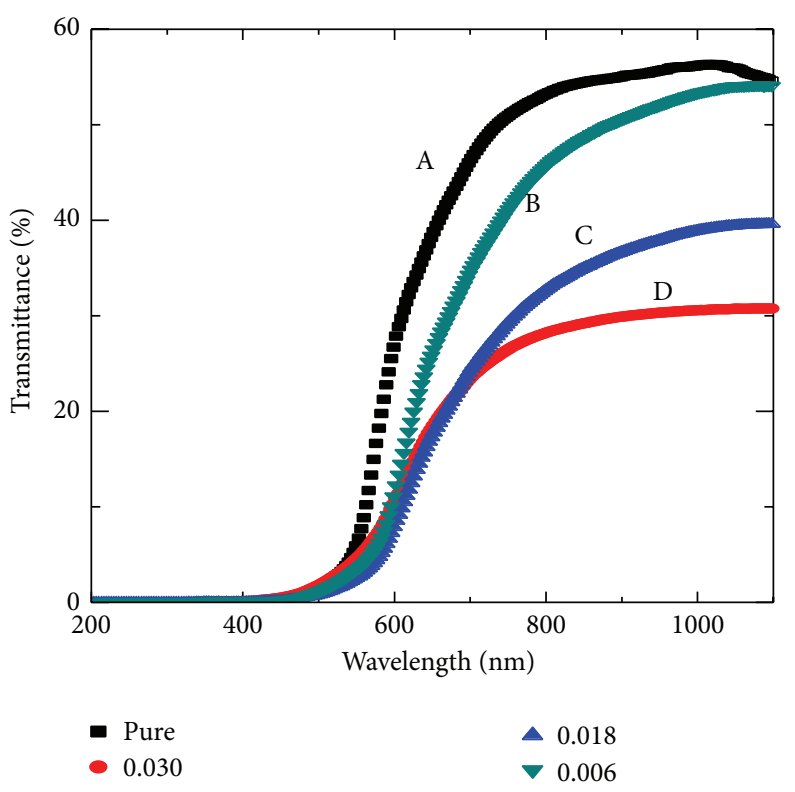

FIGURE 8: The UV-Visible transmission curves of Ru doped hematite samples grown on FTO glass substrate at $95^{\circ} \mathrm{C}$ for $24 \mathrm{~h}$, where A is undoped, $\mathrm{B}$ is $0.006 \mathrm{~g}, \mathrm{C}$ is $0.018 \mathrm{~g}$, and $\mathrm{D}$ is $0.03 \mathrm{~g}$ of $\mathrm{RuCl}_{3} \cdot x \mathrm{H}_{2} \mathrm{O}$.

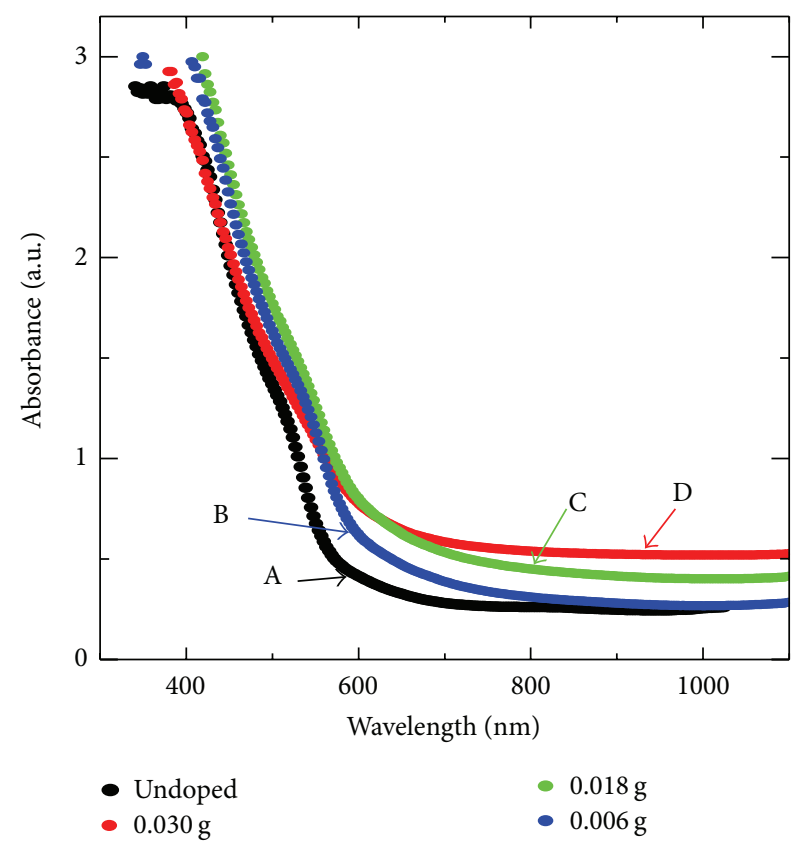

FIgURE 9: The UV-Visible absorption curves of Ru doped hematite nanorods grown on FTO glass substrate at $95^{\circ} \mathrm{C}$ for $24 \mathrm{~h}$, where A is an undoped sample, and $\mathrm{B}, \mathrm{C}$, and $\mathrm{D}$ are produced using $0.006 \mathrm{~g}$, $0.018 \mathrm{~g}$, and $0.030 \mathrm{~g}$ of $\mathrm{RuCl}_{3} \cdot x \mathrm{H}_{2} \mathrm{O}$ precursor, respectively.

\section{Acknowledgments}

This work was sponsored by the South African Nuclear Human Asset and Research Programme (SANHARP) in collaboration with iThemba LABS-MRD and University of 


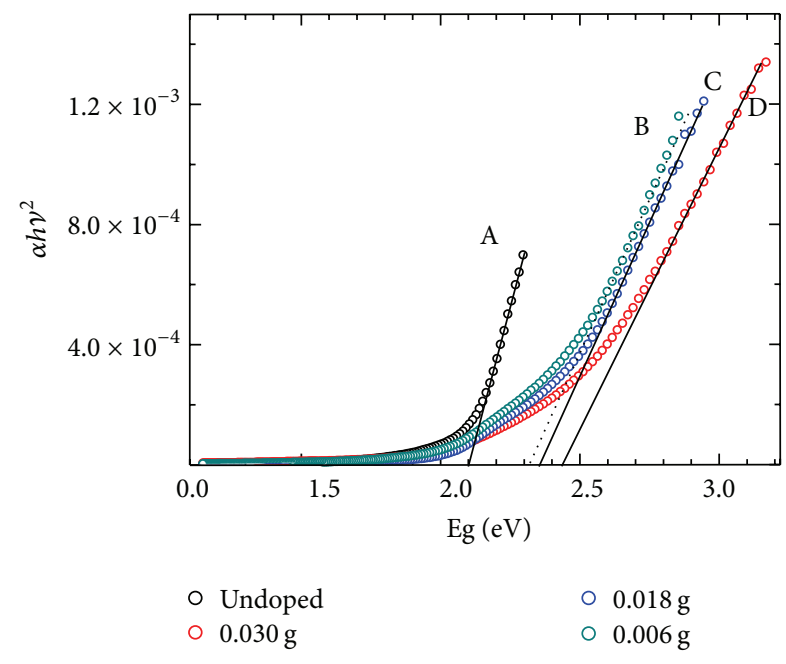

FIGURE 10: The band gap estimation deduced from plots of $(\alpha h v)^{2}$ as a function of photon energy $(h \nu)$ for Ru doped hematite thin films grown on FTO glass substrate at $95^{\circ} \mathrm{C}$ for $24 \mathrm{~h}$, where $\mathrm{A}$ is undoped, $\mathrm{B}$ is $0.006 \mathrm{~g}, \mathrm{C}$ is $0.018 \mathrm{~g}$, and $\mathrm{D}$ is $0.03 \mathrm{~g}$ of $\mathrm{RuCl}_{3} \cdot x \mathrm{H}_{2} \mathrm{O}$.

Zululand, South Africa, and the National Research Foundation (South Africa).

\section{References}

[1] L. Vayssieres, "Advanced semiconductor nanostructures," Comptes Rendus Chimie, vol. 9, no. 5-6, pp. 691-701, 2006.

[2] Y. Matsumoto, "Energy positions of oxide semiconductors and photocatalysis with iron complex oxides," Journal of Solid State Chemistry, vol. 126, no. 2, pp. 227-234, 1996.

[3] C. C. Chai, J. Peng, and B. P. Yan, "Characterization of $\alpha$ $\mathrm{Fe}_{2} \mathrm{O}_{3}$ thin films deposited by atmospheric pressure CVD onto alumina substrates," Sensors and Actuators, B: Chemical, vol. 34, no. 1-3, pp. 412-416, 1996.

[4] B. Zhao, Y. Wang, H. Guo et al., "Iron oxide (III) nanoparticles fabricated by electron beam irradiation method," Materials Science-Poland, vol. 25, no. 4, pp. 1143-1148, 2007.

[5] G. Dascalu, I. Mihaila, O. Caltun, and G. Popa, “The influence of the thermal treatment on the microstructures of thin cobalt ferrite films," Journal of Advanced Research in Physics, vol. 1, no. 1, Article ID 011002, 2010.

[6] S. Joshi, R. Nawathey, V. N. Koinkar et al., "Pulsed laser deposition of iron oxide and ferrite films," Journal of Applied Physics, vol. 64, no. 10, pp. 5647-5649, 1988.

[7] M. Mohapatra and S. Anand, "Synthesis and applications of nano-structured iron oxides/hydroxides-a review," International Journal of Engineering, Science and Technology, vol. 2, no. 8, pp. 127-146, 2010.

[8] D. Sharma, S. Upadhayy, S. Choudhary, V. R. Satsangi, R. Shrivastav, and S. Dass, "Enhancement of photoelectric conversion properties of $\alpha-\mathrm{Fe}_{2} \mathrm{O}_{3} / \mathrm{Cu}_{2} \mathrm{O}$ bilayered photoanode," International Journal of Materials, Mechanics and Manufacturing, vol. 2, no. 1, pp. 51-55, 2014.

[9] T. Lindgren, H. Wang, N. Beermann, L. Vayssieres, A. Hagfeldt, and S.-E. Lindquist, "Aqueous photoelectrochemistry of hematite nanorod array," Solar Energy Materials and Solar Cells, vol. 71, no. 2, pp. 231-243, 2002.
[10] N. Beermann, L. Vayssieres, S.-E. Lindquist, and A. Hagfeldt, "Photoelectrochemical studies of oriented nanorod thin films of hematite," Journal of the Electrochemical Society, vol. 147, no. 7, pp. 2456-2461, 2000.

[11] H. C. Jo, K. M. Kim, H. Cheong, S.-H. Lee, and S. K. Deb, "In situ raman spectroscopy of $\mathrm{RuO}_{2} \cdot x \mathrm{H}_{2} \mathrm{O}$," Electrochemical and Solid-State Letters, vol. 8, no. 4, pp. E39-E41, 2005.

[12] L. Vayssieres, "One-dimensional confinement effect in hematite quantum rod arrays," in Solar Hydrogen and Nanotechnology, L. Vayssieres, Ed., vol. 6340 of Proceedings of SPIE, pp. 1-336, 2006.

[13] L. Vayssieres, C. Sathe, S. M. Butorin, D. K. Shuh, J. Nordgren, and J. Guo, "One-dimensional quantum-confinement effect in $\alpha-\mathrm{Fe}_{2} \mathrm{O}_{3}$ ultrafine nanorod arrays," Advanced Materials, vol. 17, no. 19, pp. 2320-2323, 2005.

[14] D. G. Rncourt, "Accurate site populations from Mössbauer spectroscopy," Nuclear Instruments and Methods in Physics Research B: Beam Interactions with Materials and Atoms, vol. 44, no. 2, pp. 199-210, 1989.

[15] R. Zboril, M. Mmashlan, and D. Petridis, "Iron(III) oxides from thermal processes synthesis, structural and magnetic properties, Mössbauer spectroscopy characterization, and applications," Chemistry of Materials, vol. 14, no. 3, pp. 969-982, 2002.

[16] Ö. Helgason, I. Ayub, F. J. Berry, and E. Crabb, "Phase transitions of ruthenium-doped iron oxide studied by $57 \mathrm{Fe}$ Mössbauer spectroscopy at elevated temperatures," Hyperfine Interactions, vol. 141-142, no. 141, pp. 291-295, 2002. 

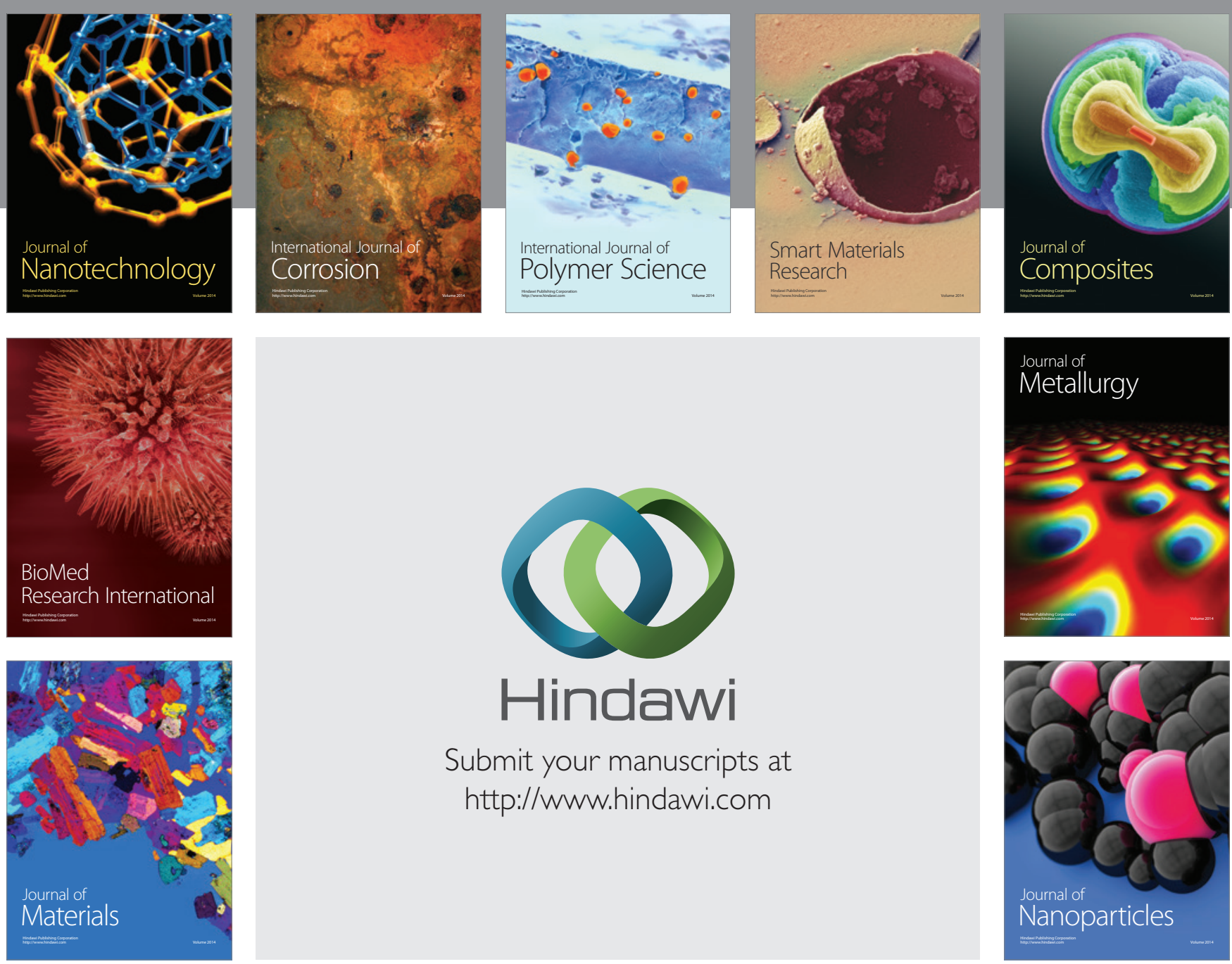

Submit your manuscripts at http://www.hindawi.com
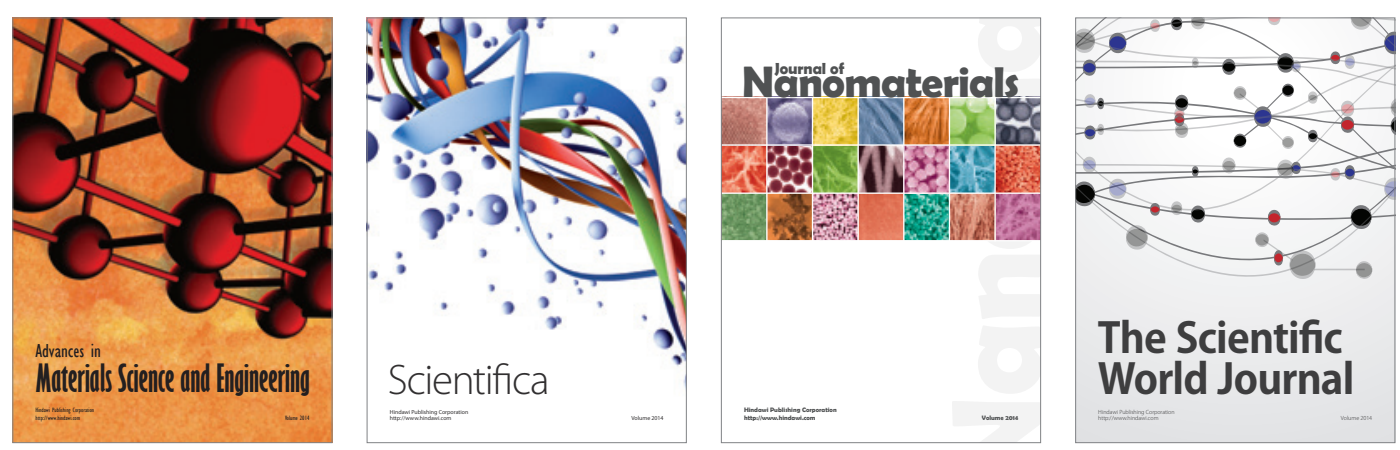

\section{The Scientific World Journal}
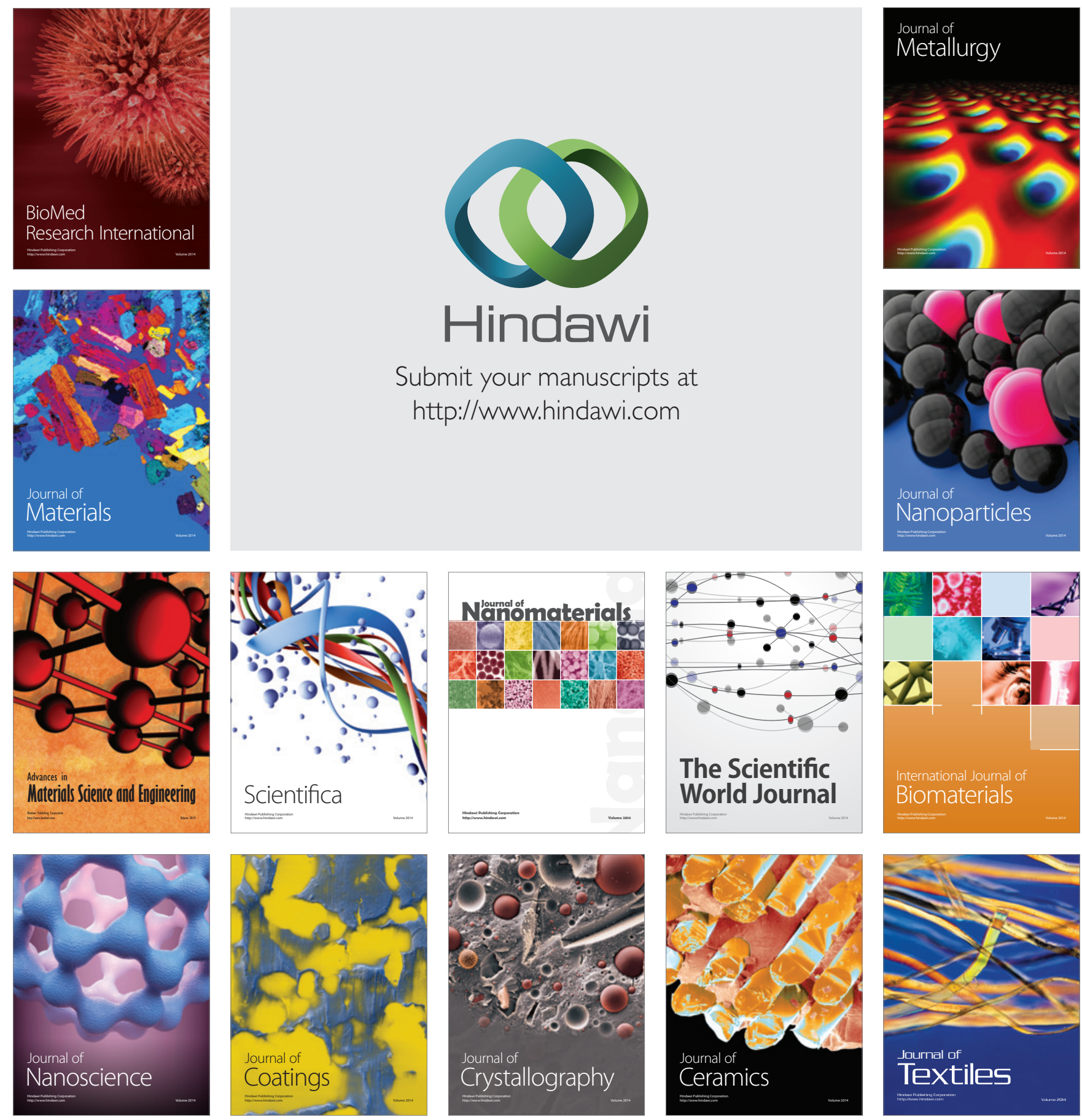